\title{
High prevalence of qnrA and qnrB genes among fluoroquinolone-resistant Escherichia coli isolates from a tertiary hospital in Southern Nigeria
}

\author{
Chibuzor M. Nsofor ${ }^{1}$, Mirabeau Y. Tattfeng ${ }^{1,2}$ and Chijioke A. Nsofor ${ }^{3^{*}}$
}

\begin{abstract}
Background: This study was aimed to determine the prevalence of qnr genes among fluoroquinolone-resistant Escherichia coli (FREC) isolates from Nigeria. Antimicrobial susceptibility testing was performed by disc diffusion technique. Polymerase chain reaction was used to identify Escherichia coli (E. coli) and for the detection of qnr genes.

Results: A total of 206 non-duplicate E. coli were isolated from 300 clinical specimens analyzed. In all, 30 (14.6\%) of these isolates were FREC; the resistance to fluoroquinolones among these 30 FREC showed $80 \%$ (24), 86.7\% (26), $86.7 \%$ (26), 100\% (30), 86.7\% (26), 93.3\% (28) and 86.7\% (26) were resistant to pefloxacin, ciprofloxacin, sparfloxacin, levofloxacin, nalidixic acid, ofloxacin and moxifloxacin, respectively. The distribution of FREC among the various sample sources analyzed showed that 14\%, 10\%, 13.3\%, 16.7\% and 20\% of the isolates came from urine, stool, high vaginal swab, endo cervical swab and wound swab specimens, respectively. More FREC were isolated from female samples $73.3 \%$ (22) compared to male samples $26.7 \%$ (8) and were more prevalent among the age group 26-35 years (40\%). Twenty eight out of the 30 (93.3\%) FREC isolates possessed at least one fluoroquinolone resistance gene in the form of qnrA 10 (33.3\%) and qnrB 18 (60\%), respectively; qnrS was not detected among the FREC isolates analyzed and $13.5 \%$ of the isolates possessed both the qnrA and qnrB genes. Phylogenetic analysis showed that these isolates were genetically diverse.
\end{abstract}

Conclusions: These findings suggest a possible resistance to fluoroquinolone is of high interest for better management of patients and control of antimicrobial resistance in Nigeria.

Keywords: Escherichia coli, Fluoroquinolone-resistant genes, Nigeria

\section{Background}

Since it was discovered in 1885, Escherichia coli has been subjected to comprehensive studies and become one of the best understood and characterized organisms (Kuhnert et al. 2000). Despite the vast knowledge accumulated throughout the last decades, E. coli is still one of the major causes of infection in humans. In addition to

\footnotetext{
*Correspondence: nsoforac@gmail.com; chijioke.nsofor@futo.edu.ng ${ }^{3}$ Department of Biotechnology, Federal University of Technology Owerri, Owerri, Imo State, Nigeria

Full list of author information is available at the end of the article
}

urinary tract infection (UTI), where it is responsible for most of the reported cases, E. coli has been associated with a number of other diseases including gastrointestinal diseases, pneumonia and meningitis (Kaper et al. 2004).

The fluoroquinolones comprise one of the most widely used groups of antibacterial agents in Nigeria (Alade et al. 2018); however, concerns have developed about the emergence of bacteria resistant to these broad-spectrum antibiotics. E. coli uses different mechanisms to provide resistance to quinolones, including (1) the accumulation of mutations in the genes encoding quinolone target 
DNA gyrase and topoisomerase IV; (2) a decrease of intracellular concentration of fluoroquinolones by porins down-regulation or modification of the efflux pumps activity; and (3) the acquisition of plasmid quinolone resistance genes (Zhao et al. 2015). Studies have shown that the emergence of plasmid-mediated quinolone resistance (PMQR) may contribute by several means to the rapid increase in bacterial resistance to quinolones. Plasmid-mediated quinolone resistance genes qnrA, qnrB and qnrS encode pentapeptide repeat protein and have ability to protect DNA gyrase from quinolone inhibition (Kurnia et al. 2018). About 100 qnr genes variants have been described mainly from Enterobacteriaceae and grouped into five distinct families: qnrA, qnrB, qnrC, qnrD and qnrS (Strahilevitz et al. 2009; Salah et al. 2019).

Hospital wards, especially those in low-income countries such as Nigeria, where infection prevention and control protocols are lacking, have become the main foci for developing multidrug resistance in bacteria such as E. coli (Nsofor and Iroegbu 2013). Increasing rates of $E$. coli resistance to fluoroquinolone class of antibiotics are of great concern not only to healthcare workers (HCWs) but to the public. This is because they are the drug of choice for the treatment of very stubborn infection. The poor screening of these multidrug resistance (MDR) pathogens in the hospitals coupled with poor antibiotic stewardship and surveillance systems has increased their burden in the country. The traditional antibiotic susceptibility testing protocol being used currently in many clinical laboratories in Nigeria may not adequately detect bacteria harboring fluoroquinolone resistance genes. Therefore, this study was aimed to determine the prevalence of qnr genes among fluoroquinolone-resistant $E$. coli (FREC) clinical isolates from Madonna University Teaching Hospital, a tertiary health intuition in Southern Nigeria. The findings from this work will help to better understand and potentially predict trends in antibiotic resistance patterns, as well as establish adequate infection control measure in the region.

\section{Methods}

\section{Bacterial isolates}

A total of 206 consecutive non-duplicate $E$. coli were isolated from 300 various clinical specimens at Madonna University Teaching Hospital Elele, a tertiary hospital in Rivers State, Southern Nigeria, from October 2018 to March 2019. The specimens included urine, stool, high vaginal swab, endo cervical swab and wound swab. Criteria used to decide the suitability of patients for sample collection were as follows: (1) outpatients, emergency patients or inpatients who were admitted with infections within $48 \mathrm{~h}$ of diagnosis; (2) patients not hospitalized for the preceding 90 days; (3) individuals with no long-term indwelling catheters; and (4) patients who received antimicrobial agents for $\leq 72 \mathrm{~h}$. Standard microbiological methods were used to isolate and purify bacterial isolates on MacConkey or eosin methylene blue (EMB) media (Cheesbrough 2000). No antibiotic was included in the agar plates used for the cultivation. E. coli strains were fully identified by $16 \mathrm{~s}$ rRNA PCR and stored at $-20^{\circ} \mathrm{C}$ in a nutrient agar slant prior to molecular characterization. All sampling procedures were in accordance with guidelines of the National Health Research Ethics Committee, Nigeria (www.nhrec.net), and the protocol of this study was approved by the Ethics Committee of Madonna University Elele, Nigeria. The patients gave oral consent for their specimens to be used in the study. The sampling and phenotypic characterization was carried out at Madonna University Nigeria, while molecular characterization was carried out at Niger Delta University Nigeria.

\section{Antibiotics susceptibility testing}

The antibiotics susceptibility pattern of the isolates was determined using the disc diffusion method on MuellerHinton agar (Oxoid, England). Inhibition zone diameter values were measured and interpreted using the European Committee on Antimicrobial Susceptibility Testing breakpoint (EUCAST 2018). The isolates were tested against nine antibiotics, namely pefloxacin, ciprofloxacin, sparfloxacin, levofloxacin, nalidixic acid, ofloxacin, moxifloxacin, oxacillin and erythromycin (Oxoid, England). E. coli ATCC 25922 strain was used as a control for antibiotic susceptibility testing.

\section{Extraction of bacterial DNA}

DNA extraction was performed using a boiling technique. Briefly, overnight broth culture of the bacterial isolate in Luria-Bertani (LB) medium was transferred into 1.5-ml Eppendorf tube and was centrifuged at $14,000 \mathrm{rpm} / \mathrm{min}$ for $3 \mathrm{~min}$. The supernatant was discarded, and $1000 \mu \mathrm{l}$ of $0.5 \%$ normal saline was added to the pellet for cell wall weakening and was vortexed on eltech XH-B vortexer. The cells were re-suspended in 500ul of normal saline and heated at $95^{\circ} \mathrm{C}$ for $20 \mathrm{~min}$ to release bacterial nucleic acid. The heated bacterial suspension was cooled on ice and centrifuged at 14,000 rpm/ min for $3 \mathrm{~min}$. DNA was then precipitated in $250 \mu \mathrm{L}$ of absolute ethanol, washed twice in $1000 \mu \mathrm{L}$ of ethanol $75 \%$, dried and re-suspended in $100 \mu \mathrm{L}$ of sterile water. The extracted genomic DNA was quantified using the NanoDrop 1000 spectrophotometer.

\section{Molecular detection of qnr genes}

PCR assays were performed for the detection of qnr resistance genes including qnrA, qnrB and qnrS. The primers used to detect qnr genes were selected from 
previously described sequences by Cattoir et al. (2007). PCR was done in a total volume of $25 \mu \mathrm{L}$ containing $3 \mu \mathrm{L}$ DNA template, $2.5 \mu \mathrm{L}$ PCR buffer (1X), $1 \mu \mathrm{L}$ deoxyribonucleotide triphosphates solution (dNTPs, $200 \mu \mathrm{M}$ ), $1.5 \mu \mathrm{L} \mathrm{MgCl} 2(1.5 \mathrm{mM}), 0.25 \mu \mathrm{L}$ Taq DNA polymerase (1 unit) and $1 \mu \mathrm{L}$ each specific primer $(1 \mu \mathrm{M})$. PCR amplifications were carried out on a $\mathrm{T} 100^{\mathrm{TM}}$ thermal cycler (BioRad, Hercules, CA, USA). The cycling conditions were as follows: $95^{\circ} \mathrm{C}$ for $5 \mathrm{~min}$ (step 1), $95^{\circ} \mathrm{C}$ for $1 \mathrm{~min}$ (step 2), annealing for $45 \mathrm{~s}$ (step 3), $72{ }^{\circ} \mathrm{C}$ for $1 \mathrm{~min}$ (step 4) and $72{ }^{\circ} \mathrm{C}$ for $5 \mathrm{~min}$ (step 5); steps $2-4$ were repeated for 30 cycles. DNA fragments were analyzed by electrophoresis in a $1.5 \%$ agarose gel at $130 \mathrm{~V}$ for $25 \mathrm{~min}$ in $1 \mathrm{X} \mathrm{TBE}$ buffer containing ethidium bromide using 1100-bp DNA ladder (Promega, USA) as a size marker and visualized on a blue light transilluminator. The primer sequences used in this are listed in Table 1.

\section{Sequencing}

Sequencing was done using the BigDye Terminator kit on a 3510 ABI sequencer at Inqaba Biotechnological, Pretoria South Africa. The sequencing was done at a final volume of 10ul; the components included $0.25 \mu \mathrm{L}$ BigDye ${ }^{\circledR}$ terminator v1.1/v3.1, $2.25 \mu \mathrm{L}$ of $5 \times$ BigDye sequencing buffer, $10 \mu \mathrm{M}$ primer PCR primer, and 2-10 ng PCR template per $100 \mathrm{bp}$. The sequencing conditions were as follows: 32 cycles of $96{ }^{\circ} \mathrm{C}$ for $10 \mathrm{~s}, 55^{\circ} \mathrm{C}$ for $5 \mathrm{~s}$ and $60{ }^{\circ} \mathrm{C}$ for $4 \mathrm{~min}$. The primer sequences used to detect qnr genes are listed in Table 1 . The basic local alignment search tool (BLAST) program was used to compare DNA sequences against those in the National Center for Biotechnology Information (NCBI) database.

\section{Phylogenetic analysis}

Obtained sequences were edited using the bioinformatics algorithm Trace edit, and similar sequences were downloaded from the NCBI database using BLAST. These sequences were aligned using multiple alignment using fast Fourier transform (MAFFT). The evolutionary history was inferred using the neighbor-joining method in MEGA 6.0 (Saitou and Nei 1987). The bootstrap consensus tree inferred from 500 replicates (Felsenstein 1985)

Table 1 Primers used for PCR amplification of qnr genes

\begin{tabular}{lll}
\hline Target gene & Primer sequence $\left(\mathbf{5}^{\prime} \mathbf{- 3}^{\prime} \mathbf{)}\right.$ & Size $\mathbf{( b p )}$ \\
\hline qnrA & F: GATAAAGTTTTTCAGCAAGAGG & 823 \\
& R: ATCCAGATCCGCAAAGGTTA & \\
qnrB & F: ATGACGCCATTACTGTATAA & 408 \\
& R: GATCGCAATGTGTGAAGTT & \\
qnrs & F: ATGGAAACCTACAATCATAC & 428 \\
& R: AAAAACACCTCGACTTAAGT & \\
\hline
\end{tabular}

was taken to represent the evolutionary history of the taxa analyzed. The evolutionary distances were computed using the Jukes-Cantor method (Jukes and Cantor 1969).

\section{Statistical analysis}

The statistical analyses were performed using SPSS software version 21.0 (IBM Corp., USA). The results were presented as descriptive statistics in terms of relative frequency. Categorical variables were expressed as counts and percentages. The Chi-square $\left(\chi^{2}\right)$ or Fisher's exact tests were performed to analyze significant differences; $P$ value $<0.05$ was considered as statistically significant.

\section{Results}

\section{Bacterial isolates}

Out of the 300 various clinical specimens analyzed in this study, 206 (68.7\%) yielded E. coli; only one E. coli strain was picked per specimen. The distribution of the strains according to sample sources is as follows: urine 100 (48.5\%), stool 20 (9.7\%), high vaginal swab 30 (14.6\%), endo cervical swab 36 (17.5\%) and wound swab 20 (9.7\%). Specimen from female patients yielded more E. coli isolates $142(68.9 \%)$ when compared to male patients 64 (31.1\%) as shown in Table 2.

\section{Antibiotic susceptibility profile}

Among the 206 E. coli strains isolated, 30 (14.6\%) were found to be fluoroquinolone-resistant E. coli (FREC). The detailed resistance profile of the 30 FREC to individual fluoroquinolones and other antibiotics tested showed $80 \%$ (24), 86.7\% (26), 86.7\% (26), 100\% (30), $86.7 \%$ (26), 93.3\% (28), 86.7\% (26), 66.7\% (20) and $60.0 \%$ (18) were resistant to pefloxacin, ciprofloxacin, sparfloxacin, levofloxacin, nalidixic acid, ofloxacin moxifloxacin, oxacillin and erythromycin, respectively, as shown in Table 3. The distribution of FREC among the various sample sources analyzed showed that $14 \%$, $10 \%, 13.3 \%, 16.7 \%$ and $20 \%$ of the isolates came from urine, stool, high vaginal swab, endo cervical swab and wound swab specimens, respectively (Table 4). More

Table 2 The distribution of the $E$. coli isolates according to sample sources and gender

\begin{tabular}{llll}
\hline Sample source & Male (\%) & Female (\%) & Total (\%) \\
\hline Urine & $32(15.5)$ & $68(33.0)$ & $100(48.5)$ \\
Stool & $20(9.7)$ & - & $20(9.7)$ \\
High vaginal swab & - & $30(14.6)$ & $30(14.6)$ \\
Endo cervical swab & - & $36(17.5)$ & $36(17.5)$ \\
Wound swab & $12(5.8)$ & $8(3.9)$ & $20(9.7)$ \\
Total & $64(31.1)$ & $142(68.9)$ & $206(100)$ \\
\hline
\end{tabular}


Table 3 The antibiotics susceptibility pattern of the $\mathbf{3 0}$ fluoroquinolone-resistant $E$. coli

\begin{tabular}{lll}
\hline Antibiotics & Susceptible (\%) & Resistance (\%) \\
\hline Quinolones & & \\
Pefloxacin & $6(20.0)$ & $24(80.0)$ \\
Ciprofloxacin & $4(13.3)$ & $26(86.7)$ \\
Sparfloxacin & $4(13.3)$ & $26(86.7)$ \\
Levofloxacin & $0(0.00)$ & $30(100)$ \\
Nalidixic acid & $4(13.3)$ & $26(86.7)$ \\
Ofloxacin & $2(6.7)$ & $28(93.3)$ \\
Moxifloxacin & $4(13.3)$ & $26(86.7)$ \\
Penicillin & & \\
Oxacillin & $10(33.3)$ & \\
Aminoglycosides & & $18(66.7)$ \\
Erythromycin & $12(40.0)$ & \\
\hline
\end{tabular}

Table 4 The distribution of fluoroquinolone-resistant $E$. coli among the various sample sources

\begin{tabular}{lll}
\hline Sample source & \multicolumn{1}{l}{ FREC } & \\
\cline { 2 - 3 } & Positive (\%) & Negative (\%) \\
\hline Urine & $14(14.0)$ & $86(86.0)$ \\
Stool & $2(10.0)$ & $18(90.0)$ \\
High vaginal swab & $4(13.3)$ & $26(86.7)$ \\
Endo cervical swab & $6(16.7)$ & $30(83.3)$ \\
Wound swab & $4(20.0)$ & $16(80.0)$ \\
Total & $30(14.6)$ & $176(85.4)$ \\
\hline
\end{tabular}

FREC were isolated from female samples $73.3 \%$ (22) compared to male samples $26.7 \%$ (8) and were more prevalent among the age group 26-35 years (40\%).

\section{Distribution of qnr genes}

Electrophoresis analysis revealed that 28 out of the 30 (93.3\%) FREC isolates harbored at least one fluoroquinolone resistance gene: qnrA 10 (33.3\%) and qnrB 18 (60\%), respectively; qnrS was not detected among the FREC analyzed. The concomitant presence of two qnr genes (qnrA and qnrB) was detected in $13.5 \%$ of the isolates. E. coli strains from urine specimen harbored the highest number qnr genes, 16, while strains from wound swab had 6 genes and those from stool, HVS and ECS had 2 qnr genes, respectively (Table 5). A representative of the agarose gel electrophoresis of each of the qnr genes is shown in Figs. 1, 2, 3. Phylogenetic analysis showed that these isolates were not clonally related and were genetically diverse (Fig. 4).
Table 5 The distribution of fluoroquinolone-resistant genes, qnrA and qnrB among the sample sources

\begin{tabular}{llll}
\hline Sample source & $\begin{array}{l}\text { qnrA } \\
\text { Number } \\
\text { positive (\%) }\end{array}$ & $\begin{array}{l}\text { qnrB } \\
\text { Number } \\
\text { positive (\%) }\end{array}$ & Total (\%) \\
\hline Urine & $6(37.5)$ & $10(62.5)$ & $16(100.0)$ \\
Stool & 0 & $2(100.0)$ & $2(100.0)$ \\
HVS & 0 & $2(100.0)$ & $2(100.0)$ \\
ECS & $2(100.0)$ & 0 & $2(100.0)$ \\
Wound & $2(33.3)$ & $4(66.7)$ & $6(100.0)$ \\
Total & $10(35.7)$ & $18(64.3)$ & $28(100.0)$ \\
\hline
\end{tabular}
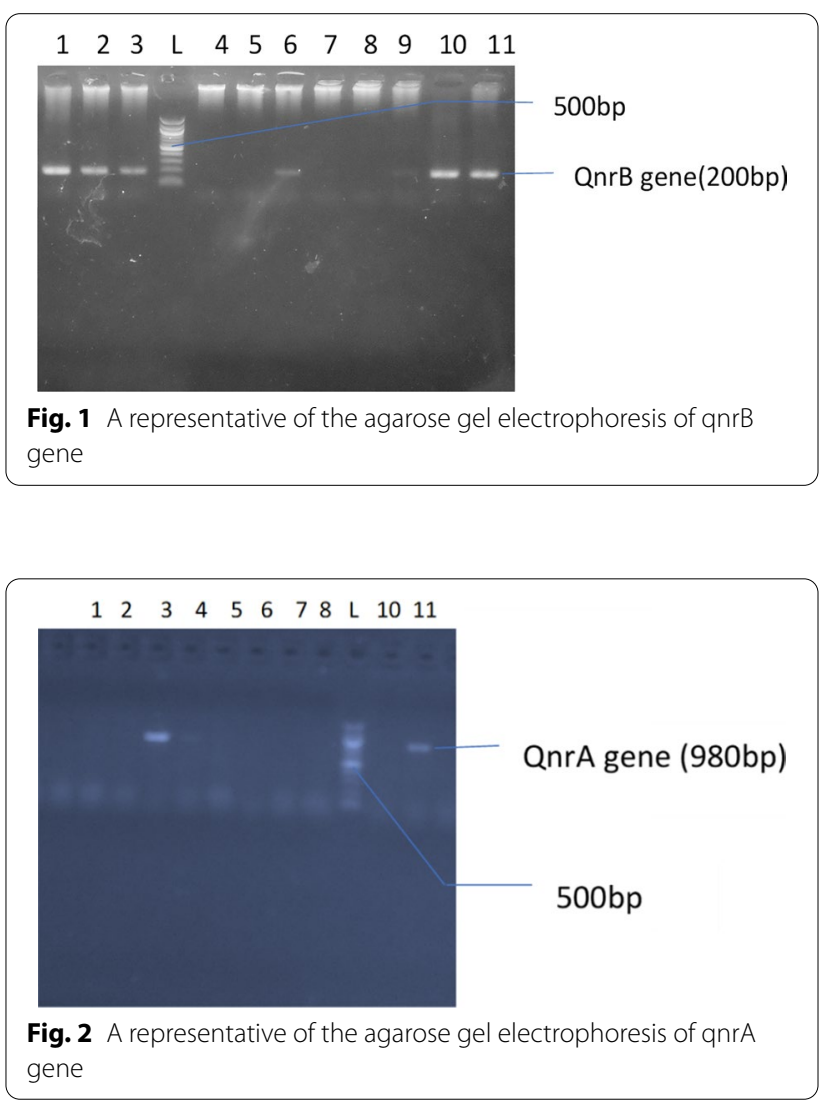

\section{Discussion}

The extensive use of fluoroquinolone antibiotics in human medicine is associated with increasing emergence of quinolone resistance strains (Correia et al. 2017). Here, we investigated the fluoroquinolone resistance among a collection of clinical isolates from Madonna University Teaching Hospital Nigeria. In all, $14.6 \%$ of the isolates were found to be FREC, while $93.3 \%$ of the isolates harbored at least one fluoroquinolone resistance genes: qnrA $33.3 \%$ and qnrB 60\%, respectively; qnrS was not detected among the FREC analyzed. This indicates low 


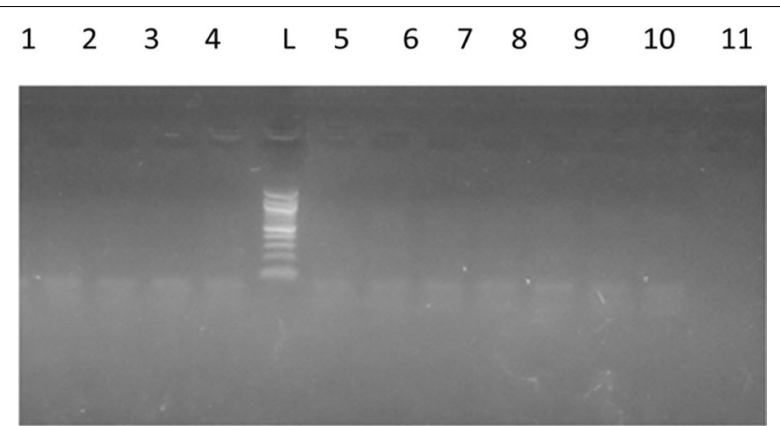

Fig. 3 A representative of the agarose gel electrophoresis of qnrS gene

level resistance to fluoroquinolones but high rate of qnr genes among the FREC.

The occurrence of qnr genes observed in this study is higher than those reported in other neighboring African countries; in Togo, Salah et al. (2019) reported 67.03\% rate of qnr genes in E. coli (qnrB 47.74\%, qnrS $47.10 \%$ and qnrA 2.58\%), while Guessennd et al. (2008) reported $31.2 \%$ with $14.6 \%$ for qnrB, $9.9 \%$ for qnrA and $2.7 \%$ for qnrS in Côte d'Ivoire. In a study conducted in Niger, Moumouni et al. (2017) showed a $44.4 \%$ occurrence of qnr genes in $E$. coli with $64.3 \%$ for qnrS, $26.2 \%$ for qnrB and $9.5 \%$ for qnrA, while Jamali et al. (2014), showed that the prevalence of qnr gene was $2.6 \%$ (1.7\% qnrS and $0.9 \%$ $\mathrm{qnrB}$ ) in a Moroccan community. Studies conducted in some Asian countries showed that the frequencies of qnr genes are considerably low; in China, Wang et al. (2008) reported the incidences of qnr as $7.5 \%$ among ciprofloxacin-resistant $E$. coli, with qnrA, qnrB and qnrS detected either alone or in combination in $3.8 \%, 4.7 \%$ and $3.8 \%$ of these isolates, respectively. In Korea, Shin et al. (2008) reported that $5.6 \%$ of $E$. coli ciprofloxacin-resistant isolates contained only qnrB. Jeong et al. (2005) reported that the prevalence of qnrA in Korea was $0.8 \%$ in E. coli isolates (ciprofloxacin susceptible and resistant) between 2001 and 2003. These data show that the distribution of

\section{E5 Escherichia coli}

MN704605 Escherichia coli strain SRA3

E4 Escherichia coli

E3 Escherichia coli

E2 Escherichia coli

E1 Escherichia coli

MH734837 Escherichia coli strain B16_27-F_B09_06

Fig. 4 Phylogenetic tree showing the genetic diversity of Escherichia coli isolates 
qnr genes in $E$. coli varies from one region to the other. The regionally diverse and wide distribution of qnr genes in $E$. coli suggests that resistance evolved independently on many occasions. However, the rational and controlled use of fluoroquinolone antibiotics is an effective way to control the development of higher levels of resistance.

Though similar studies usually detect the three major qnr genes (qnrA, qnrB, qnrS), our study did not detect qnrS in any of the isolates; however, it is in agreement with some studies (Seo et al. 2010; Yang et al. 2014; Moghadasi et al. 2016), which has shown that qnrB is most common qnr genes; our findings showed highest occurrence of qnrB (60\%). The mobile characteristic of PMQR genes allows them to move across plasmids or spread from one species to another via moving elements. Although they provide a low level of quinolone resistance, they can promote mutations of target enzymes such as DNA gyrase and topoisomerase IV. The horizontal transmission of these plasmids to susceptible bacteria should be of concern, particularly in its ability to aid in the dissemination of antibiotic resistances (Lamikanra et al. 2011). Various reasons have been adduced for this spread, of which the high level of quinolones use in human medicine has been considered an important factor (Poirel et al. 2012). As reported by various researchers, another factor of concern associated with the advent of quinolone resistance is their close relation with other agents, especially the expression of extendedspectrum beta lactamases (ESBLs) and aminoglycosides (Zhang et al. 2012; Andres et al. 2013; Liu et al. 2013). It is quite unfortunate that this biologic relationship among these agents has caused a suitable opportunity for dissemination of multidrug resistance among the Enterobacteriaceae, thus resulting in restrictions on treatment choices. Therefore, this should be of concern to the physicians when prescribing quinolones that the resistance to cephalosporins and aminoglycosides and other resistance forms which are associated with PMQRs may occur as well (Robicsek et al. 2006).

The antibiotic resistance profile of the isolates encoding qnr genes showed 80\%, 86.7\%, 86.7\%, 100\%, 86.7\%, 93.3\% and $86.7 \%$ resistance to pefloxacin, ciprofloxacin, sparfloxacin, levofloxacin, nalidixic acid, ofloxacin and moxifloxacin, respectively. These rates are similar to those observed in Togo ( $90.48 \%$ for nalidixic acid and 93.46\% for ciprofloxacin) (Salah et al. 2019) but higher than those observed in Morocco (57\% for nalidixic acid and $78 \%$ for ciprofloxacin) (Jamali et al. 2014) and in Mexico (41.1\% for nalidixic acid and 29.4\% for ciprofloxacin) (Silva-Sanchez et al., 2013). The higher resistance rate of the qnr-positive strains observed in this study could be explained by the concomitant presence of two qnr gene groups, thus inducing an additive effect on the minimal inhibiting concentrations (MICs) of these different molecules. In addition, qnr-positive isolates showed more resistance to erythromycin (60.0\%). This may be explained by the fact that plasmid-mediated quinolone resistance is associated with integrons bearing resistance determinants to several other antibiotics such as beta lactams and aminoglycosides (Minh Vien et al. 2009, Iabadene et al. 2008). It is worthy to note that in this study, no qnr genes were detected in $6.7 \%$ of the FREC isolates; this can suggest the presence of another mechanism of resistance to quinolones such as mutations in the gyrase and topoisomerase IV genes (Jacoby et al. 2014, Redgrave et al. 2014).

Phylogenetic analysis showed that the FREC isolates exhibited genetic diversity. As the phylogenetic tree did not show any major clusters among the isolates, the clonal transfer of resistant strains cannot be inferred from this study. As whether the resistance genes could be transmitted horizontally in vehicles such as plasmids, further studies should be conducted.

\section{Conclusions}

In conclusion, our result revealed a high rate of qnrA and qnrB among FREC isolates from Southern Nigeria. These qnr gene-positive strains were highly resistant to pefloxacin, ciprofloxacin, sparfloxacin, levofloxacin, nalidixic acid, ofloxacin and erythromycin. The plasmid-mediated quinolone resistance genes and their association with aminoglycoside resistance contribute to the spread of multidrug resistance due to their easy transfer between bacteria. Their wide dissemination impairs treatment outcome of common infections in community and hospital settings. These findings suggest the strengthening of the public health policies in Nigeria in order to prevent, monitor and control antimicrobial resistance through the implementation of an antibiotic resistance surveillance system. Further studies on plasmid profiling and conjugation experiments or hybridization to confirm the presence of target genes on plasmid are recommended.

\section{Abbreviations}

MDR: multidrug resistance; PCR: polymerase chain reaction; BLAST: basic local alignment search tool; NCBI: National Center for Biotechnology Information; MAFFT: multiple alignment using fast Fourier transform.

\section{Acknowledgements}

We acknowledge the management of Madonna University Teaching Hospital Elele for granting us access to patients attending their hospital and the patients for content to use their clinical specimens for the study.

\section{Authors' contributions}

This paper is part of M.Sc. research project of CMN at Madonna University Nigeria. MYT and CMN designed the work; CMN performed the experiments; CMN, MYT and CAN analyzed and interpreted the data; CMN and CAN wrote the paper. All authors have read and approved the manuscript. 


\section{Funding}

The authors received no funding for this project.

\section{Availability of data and materials}

Supporting data are available on request.

\section{Ethics approval and consent to participate}

The protocol of this study was approved by the Ethics Committee of Madonna University Elele Nigeria (the committee's reference number is not applicable). The verbal consent obtained was approved by the ethics committee. All sampling procedures were in accordance with guidelines of the National Health Research Ethics Committee, Nigeria (www.nhrec.net), and the patients gave consent for their specimens to be used in the study.

\section{Competing interests}

The authors declare no competing interests.

\section{Author details}

${ }^{1}$ Department of Medical Laboratory Science, Madonna University Elele, Elele, Rivers State, Nigeria. ${ }^{2}$ Department of Medical Laboratory Science, Niger Delta University, Wilberforce Island, Amassoma, Bayelsa State, Nigeria. ${ }^{3}$ Department of Biotechnology, Federal University of Technology Owerri, Owerri, Imo State, Nigeria.

Received: 24 April 2020 Accepted: 21 December 2020

Published online: 18 January 2021

\section{References}

Alade T, Abdu A, Tattfeng M (2018) Detection of quinolone resistance genes (QnrA, QnrB and QnrS) in Klebsiella Sp. isolates from clinical samples in Bayelsa State, Nigeria. Int J Sci Res 7(8). ISSN No 2277 - 8179 | IF: 4.758 | IC Value: 93.98

Andres P, LuceroSoler-Bistué Guerriero Albornoz Tran Zorreguieta Galas Corso CALETAMA (2013) Differential distribution of plasmidmediated quinolone resistance genes in clinical enterobacteria with unusual phenotypes of quinolone susceptibility from Argentina. Antimicrob Agents Chemother 57:2467-2475

Cattoir V, Poirel L, Rotimi V, Soussy CJ, Nordmann P (2007) Multiplex PCR for detection of plasmid-mediated quinolone resistance qnr genes in ESBLproducing enterobacterial isolates. J Antimicrob Chemother 60(2):394-397

Cheesbrough M (2000) District laboratory practice in tropical countries, Part 2 Cambridge University Press, Cambridge, p 434

Correia S, Poeta P, Hebraud M, Capelo JL, Igrejas G (2017) Mechanisms of quinolone action and resistance: where do we stand? J Med Microbiol 66(5):551-559

Guessennd N, Bremont S, Gbonon V, Kacou-Ndouba A, Ekaza E, Lambert T (2008) Qnr-type quinolone resistance in extended-spectrum beta-lactamase producing enterobacteria in Abidjan, Ivory Coast. Pathologie-biologie 56(7-8):439-446

labadene H, Messai Y, Ammari H, Ramdani-Bouguessa N, Lounes S, Bakour R et al (2008) Dissemination of ESBL and Qnr determinants in Enterobacter cloacae in Algeria. J Antimicrob Chemother 62(1):133-136. Redgrave LS, Sutton SB, Webber MA, Piddock LJV. Fluoroquinolone

Jacoby GA, Strahilevitz J, Hooper DC (2014) Plasmid-mediated quinolone resistance. Microbiol Spectr 2(5)

Jamali L, Haouzane F, Bouchakour M, Oufrid S, Ghazlane Z, El Mdaghri N (2014) Prévalence des gènes de résistance plasmidique aux quinolones chez des entérobactéries communautaires isolées au Maroc [Prevalence of plasmid mediated quinolone resistance genes among enterobacteria isolates in Moroccan community]. Int J Innov Sci Res 11(2):387-399

Jeong JY, Yoon HJ, Kim ES (2005) Detection of qnr in clinical isolates of Escherichia coli from Korea. Antimicrob Agents Chemother 2005(49):2522-2524

Kaper JB, Nataro JP, Mobley HL (2004) Pathogenic Escherichia coli. Nat Rev Microbiol J 2:123-140

Kuhnert P, Boerlin P, Frey J (2000) Target genes for virulence assessment of Escherichia coli isolates from water, food and the environment. FEMS Microbiol Rev 24:107-117

Kurnia RS, Indrawati A, Mayasari NLPI, Priadi A (2018) Molecular detection of genes encoding resistance to tetracycline and determination of plasmid-mediated resistance to quinolones in avian pathogenic Escherichia coli in Sukabumi, Indonesia. Veterin World 11(11):1581-1586

Lamikanra A, Crowe JL, Lijek RS et al (2011) Rapid evolution of fluoroquinoloneresistant Escherichia coli in Nigeria is temporally associated with fluoroquinolone use. BMC Infect Dis 11(1):1-10

Liu BT, Liao XP, Yue L, Chen XY, Li L, Yang SS, Sun J, Zhang S, Liao SD, Liu YH (2013) Prevalence of b-lactamase and 165 rRNA methylase genes among clinical Escherichia coli isolates carrying plasmid-mediated quinolone resistance genes from animals. Microb Drug Resist 19:237-245

Minh Vien LT, Baker S, Phuong Thao LT, Phuong Tu LT, Thu Thuy C, Thu Nga TT et al (2009) High prevalence of plasmid-mediated quinolone resistance determinants in commensal members of the Enterobacteriaceae in Ho Chi Minh City. Vietnam J Med Microbiol 58(12):1585-1592

Moghadasi M, Mirzaee M, Mehrabi MR (2016) Frequency of quinolone resistance and $\mathrm{qnrB}$ and qnrC genes in clinical isolates of Klebsiella pneumoniae. J Med Bacteriol 5(5-6):39-45

Moumouni A, Diagbouga S, Nadembèga C, Metuor Dabire A, Ouattara K, Zohoncon T (2017) Quinolone resistance (qnr) genes in fecal carriage of extended Spectrum beta-lactamases producing Enterobacteria isolated from children in Niger. Curr Res Microbiol Biotechnol 5(1):953-957

Nsofor CA, Iroegbu CU (2013) Antibiotic resistance profile of Escherichia coli isolated from five major geopolitical zones of Nigeria. J Bacteriol Res 5(3):29-34. https://doi.org/10.5897/JBR2012.035

Poirel L, Cattoir V, Nordmann P (2012) Plasmidmediated quinolone resistance; interactions between human, animal, and environmental ecologies. Front Microbiol 3(24):17

Redgrave LS, Sutton SB, Webber MA, Piddock LJV (2014) Fluoroquinolone resistance: mechanisms, impact on bacteria, and role in evolutionary success. Trends Microbiol 22(8):438-445

Robicsek A, Jacoby GA, Hooper DC (2006) The worldwide emergence of plasmidmediated quinolone resistance. Lancet Infect Dis 6:629-640

Salah FD, Diagbouga S, Metuor Dabire A, Sadji AY, Nadembega C, Moumouni A (2019) Distribution of quinolone resistance gene (qnr) inESBL-producing Escherichia coli and Klebsiella spp. in Lomé, Togo. Antimicrob Resist Infect Control 8:104. https://doi.org/10.1186/s13756-019-0552-0

Seo MR, Park YS, Pai H (2010) Characteristics of plasmid-mediated quinolone resistance genes in extended-spectrum cephalosporin resistant isolates of Klebsiella pneumoniae and Escherichia coli in Korea. Chemotherapy 56:46-53

Shin JH, Jung HJ, Lee JY, Kim HR, Lee JN, Chang CL (2008) High rates of plasmidmediated quinolone resistance $\mathrm{QnrB}$ variants among ciprofloxacin-resistant Escherichia coli and Klebsiella pneumoniae from urinary tract infections in Korea. Microb Drug Resist 14:221-226

Silva-Sanchez J, Barrios H, Reyna-Flores F, Bello-Diaz M, Sanchez-Perez A, Rojas T et al (2011) Prevalence and characterization of plasmid-mediated quinolone resistance genes in extended-spectrum $\beta$-lactamase- producing Enterobacteriaceae isolates in Mexico. Microb Drug Resist 17(4):497-505

Strahilevitz J, Jacoby GA, Hooper DC, Robicsek A (2009) Plasmid-mediated quinolone resistance: a multifaceted threat. Clin Microbiol Rev 22(4):664-689

The European Committee on Antimicrobial Susceptibility Testing, Breakpoint tables for interpretation of MICs and zone diameters, Version 8.1. http:// www.eucast.org

Wang A, Yang Y, Lu Q (2008) Presence of qnr gene in Escherichia coli and Klebsiella pneumoniae resistant to ciprofloxacin isolated from pediatric patients in China. BMC Infect Dis 2008(8):68

Yang HY, Nam YS, Lee HJ (2014) Prevalence of plasmid-mediated quinolone resistance genes among ciprofloxacin-nonsusceptible Escherichia coli and Klebsiella pneumoniae isolated from blood cultures in Korea. Can J Infect Dis Med Microbiol 25(3):163-169

Zhang Y, Yang J, Ye L, Luo Y, Wang W, Zhou W, Cui Z, Han L (2012) Characterization of clinical multidrug-resistant Escherichia coli and Klebsiella pneumoniae isolates, 2007-2009, China. Microb Drug Resist 18:465-470

Zhao L, Zhang J, Zheng B, Wei Z, Shen P, Li S, Li L, Xiao Y (2015) Molecular epidemiology and genetic diversity of fluoroquinolone-resistant Escherichia coli isolates from patients with community-onset infections in 30 Chinese county hospitals. J Clin Microbiol 53:766-770. https://doi.org/10.1128/ JCM.02594-14

\section{Publisher's Note}

Springer Nature remains neutral with regard to jurisdictional claims in published maps and institutional affiliations. 